\title{
Circulating Biomarkers of Handgrip Strength and Lung Function in Chronic Obstructive Pulmonary
} Disease

\author{
Rizwan Qaisar (D) \\ Asima Karim ${ }^{1,2}$ \\ Tahir Muhammad ${ }^{3}$ \\ 'Basic Medical Sciences, College of \\ Medicine, University of Sharjah, Sharjah, \\ United Arab Emirates; ${ }^{2}$ University of \\ Health Sciences, Lahore, Pakistan; \\ ${ }^{3}$ Department of Biochemistry, Gomal \\ Medical College, Gomal University, Dera \\ Ismail Khan, Pakistan
}

This article was published in the following Dove Press journal: International Journal of Chronic Obstructive Pulmonary Disease

Purpose: COPD is a multisystem disease and there is a need for clinical serum markers that can assess the decline in lung and muscle function in COPD. The goal of this study was to evaluate the potential association of serum club-cell protein 16 (CC16), $\alpha-1$ acid glycoprotein (AGP) and total sialic acid (TSA) with spirometry, hand-grip strength and quality of life to assess important disease outcomes.

Methods: This is a population-based cross-sectional study and data were collected from the patients at teaching hospitals of Gomal University and the University of Health Sciences in Pakistan. The study population included 1582 participants (Non-COPD; N = 788, COPD; $\mathrm{N}=845)>55$ years of age from both sexes, with data from structural interviews, clinical examinations, laboratory investigations, spirometry and hand-grip strength measurements.

Results: Serum TSA and CC16 were significant predictors of $\mathrm{FEV}_{1} \%(\mathrm{p}<0.05)$ and handgrip strength in advanced stages of COPD ( $p<0.05$ each) in both sexes. Men had higher absolute and adjusted hand-grip strength than women in all groups $(\mathrm{p}<0.05)$. Hand-grip strength was significantly associated with $\mathrm{FEV}_{1} \%$ in both genders $(\mathrm{p}<0.05)$ with stronger effect in women $\left(r^{2}=0.075\right)$. Serum HDL-C was an independent predictor of hand-grip strength and $\mathrm{FEV}_{1} \%(\mathrm{p}<0.05)$ in both genders. Participants with extreme problem on EQ5D parameters had more severe COPD and reduced hand-grip strength (all $\mathrm{p}$ values $<0.05$ ). Conclusion: Taken together, these studies show that the serum expressions of TSA and CC16 have correlations with spirometry and muscle decline in COPD. Further studies should be conducted to establish their efficacy in monitoring disease progression in COPD.

Keywords: club cell protein $16, \alpha-1$ acid glycoprotein, total sialic acid, EQ-5D, HDL-C

\section{Introduction}

Chronic obstructive pulmonary diseases (COPD) are frequently associated with systemic manifestations in addition to well-characterized progressive decline in the lung function. ${ }^{1}$ The loss of muscle mass and strength in these patients is partly due to systemic inflammation and sedentary lifestyle ${ }^{2,3}$ which are strong predictors of mortality in the patients with COPD. ${ }^{4}$ Hand-grip strength is a simple measure of upper limb muscles force and various respiratory and cardiovascular co-morbidities are associated with reduced hand-grip strength. ${ }^{5}$ Several previous studies have elaborated a positive association between hand-grip strength and lung functions, assessed as the forced expiratory volume in $1 \mathrm{~s}\left(\mathrm{FEV}_{1} \%\right)$ of the predicted value in the patients with $\mathrm{COPD}^{6,7}$ but the results have not always been consistent. ${ }^{8}$ This is partly because the hand-grip strength, among other factors is affected by BMI, ${ }^{9}$
Correspondence: Rizwan Qaisar Department of Basic Medical Sciences, College of Medicine, University of Sharjah, Sharjah, United Arab Emirates Tel +97। 65057254

Email rqaisar@sharjah.ac.ae 
serum metabolic profile including $\mathrm{HDL}-\mathrm{C},{ }^{10}$ smoking status ${ }^{11}$ and various co-morbidities ${ }^{5}$ which are often overlooked when correlating hand-grip strength to disease severity in patients with COPD.

Several systemic biomarkers including club cell protein 16 (CC16), $\alpha-1$ acid glycoprotein (AGP) and total sialic acid (TSA) have been associated with a decline in lung function in the patients with COPD. ${ }^{12,13}$ These serum biomarkers have shown promising association with $\mathrm{FEV}_{1} \%$ and/or hand-grip strength despite scarce data. Low levels of CC16, which is a secretory protein with anti-inflammatory properties are associated with greater decline in $\mathrm{FEV}_{1} \%{ }^{14}$ but its association with hand-grip strength in patients with COPD has not been elucidated, to our knowledge. AGP is an acute-phase protein and is reported to be a predictor of lung function in COPD,${ }^{15}$ but its association with hand-grip strength in the patients with COPD is not known. Sialic acid is a 9-carbon monosaccharide and is used as a marker of systemic inflammation in patients with COPD. ${ }^{16}$ However, search for a serum biomarker to comprehensively characterize the association between $\mathrm{FEV}_{1} \%$ and hand-grip strength in patients with COPD remains elusive.

In clinical practice, physiologic tests like spirometry, hand-grip strength and self-reported health assessment tests have been used to evaluate disease severity in COPD. ${ }^{17}$ EuroQol Five-Dimension Questionnaire (EQ-5D), a generic, health-related quality of life instrument has been used to assess the quality of life in patients with COPD. ${ }^{6,18}$

Based on these findings, we reasoned that the pathophysiological processes that occur in lung and skeletal muscle during COPD could be associated with expression of selected circulating biomarkers. More specifically, we aim to explore the relationship between serum CC16, AGP and TSA with clinically important outcome variables in COPD including $\mathrm{FEV}_{1} \%$, hand-grip strength and quality of life. Furthermore, we aim to identify the clinical relevance of hand-grip strength by testing its association with $\mathrm{FEV}_{1} \%$ and EQ-5D in patients with various stages of COPD.

\section{Methods}

\section{Study Design and Participants}

Current study is a cross-sectional analysis of the baseline data collected from the selected participants with or without COPD at the University of Health Sciences, Lahore and the Gomal Medical College, Dera Ismail Khan. The regional ethical committees at both the universities approved this study. The study population included 1582 participants (Non-COPD; $\mathrm{N}=788, \mathrm{COPD} ; \mathrm{N}=845$, Men; $\mathrm{N}=737$, Women; $\mathrm{N}=845$ ) with age range from 56 to 75 years. Data were collected from structural interviews, clinical examinations, laboratory investigations, spirometry and hand-grip strength measurements over an eightmonth time period starting January 2019. For statistical analysis, participants were divided into two groups with or without COPD. We used Global Initiative for Obstructive Lung Disease (GOLD) classification to further divide the COPD participants into 3 subgroups namely GOLD-1, GOLD-2 and GOLD-3 and 4. Written informed consent was obtained from all study participants. This study was conducted in accordance with the declaration of Helsinki. $^{19}$

\section{Definitions}

COPD was defined as $\mathrm{FEV}_{1}$ \%/forced vital capacity $(\mathrm{FVC})<$ 0.7 with persistent respiratory symptoms according to the GOLD guidelines. ${ }^{20}$ Only the patients with stable COPD were included which was characterized by absence of recent infections, hospitalization or exacerbation in past 1 month. $^{21}$ Among the patients with COPD, GOLD stage-1 was defined as $\mathrm{FEV}_{1} \geq 80 \%$ predicted, GOLD stage- 2 as $\mathrm{FEV}_{1}=50 \%$ $80 \%$ and GOLD stages- 3 and 4 as $\mathrm{FEV}_{1} \leq 50 \%$. Body mass index (BMI) was calculated as $\mathrm{kg} / \mathrm{m}^{2}$. Hypertension was defined as a systolic blood pressure $\geq 140 \mathrm{mmHg}$ or a diastolic blood pressure $\geq 90 \mathrm{mmHg}$, and/or if antihypertensive medications had been prescribed. Diabetes was defined as fasting blood glucose levels $\geq 126 \mathrm{mg} / \mathrm{dL}$ or hemoglobin $\mathrm{A} 1 \mathrm{C} \geq 6.5 \%$ and/or treatment for diabetes. Smoking status was based on the use of tobacco products (eg, cigarettes, hookah or pipe) and the participants were classified into active smokers (smoked $\geq 1$ tobacco product per day), ex-smokers (smoked $\geq 100$ tobacco products over a lifetime and smoked at least once in the last 28 days) and non-smokers (smoked $\leq 100$ tobacco products over a lifetime and did not smoke in the last 28 days). Subjects with stable COPD were included while those with unstable COPD (infection, exacerbation and/or hospitalization in the past 1 month), arthritis, myopathies and neurological diseases were excluded.

\section{Hand-Grip Strength}

Hand-grip strength was measured by a digital handgrip dynamometer (CAMRY, South El Monte, CA, USA). The participants were instructed to sit down with their elbows flexed at an angle of $90^{\circ}$ with the dynamometer 
in hand in supine position. The participants were then asked to squeeze the dynamometer with maximal strength in a smooth manner without rapid jerking or wrenching. No other body movement was allowed during the procedure. Three attempts were performed with each hand with a 60 -s rest between each attempt and the highest value was recorded for analysis.

\section{Spirometry}

The FEV1 and FVC were measured using a portable spirometer (Contec SP10, China), according to standards set by American Thoracic Society. ${ }^{22}$ The participants were instructed to inhale maximally until the lungs were full, followed by forceful exhalation into the spirometer until no air could be exhaled. ${ }^{23}$ This was done for a minimum of three times and the severity grading was based on $\mathrm{FEV}_{1} \%$ of predicted values according to the GOLD criteria into GOLD-1-4. ${ }^{24}$ The quality of life was assessed using a 5-item self-administered, scalebased questionnaire (EQ-5D) which was developed by EuroQol group. ${ }^{25}$ Only the descriptive section of EQ-5D was used which considers mobility, self-care, usual activities, pain/discomfort and anxiety/depression. Each parameter was assessed according to three functional levels: no problem, some problem or extreme problem.

\section{Blood Metabolic Profile}

Blood samples were drawn in the morning after 10-12 hrs of fasting to determine serum metabolic parameters including blood glucose and the high-density lipoproteins - cholesterol (HDL-C) using CardioCheck ${ }^{\circledR}$ equipment (Maxglobal SA, Parsippany, NJ, USA).

\section{Measurement of Serum Biomarkers}

For analysis of serum biomarkers, 18-20 participants from the non-COPD and each of the 3 subgroups of COPD participants were selected with equal representation of men and women. The numbers of participants per group or subgroup were selected based on the power $(<0.8)$ to detect $8-20 \%$ change in the serum levels of biomarkers at $p<0.05$. Serum was assayed using ELISA kits for total sialic acid (abcam, cat \# ab83375), club-cell 16 (Cat \# RD19102200, BioVendor) and $\alpha-1$ acid glycoprotein (abcam, cat \# ab108852) according to manufacturer's instructions.

\section{Statistical Analysis}

Anthropometric measurements of the participants were presented using mean and standard deviation as data met the assumption for normality. Analysis of variance was used to compare continuous variables and the chi-square test was used to determine categorical variables between the groups. Pearson correlation was employed to determine the strength of the relationship between hand-grip strength (dominant and non-dominant) and lung function ( $\mathrm{FEV}_{1} \%$, and FVC). A $p$-value $<0.05$ was considered to be statistically significant. Hand-grip strength was adjusted for age, smoking status, waist circumference, anemia, hypertension and serum HDL-C in a multiple linear regression model using following equation

$$
\begin{aligned}
\mathrm{Y}= & \beta 0+\beta 1 * \mathrm{~A}+\beta 2 * \mathrm{~B}+\beta 3 * \mathrm{C}+\beta 4 * \mathrm{D}+\beta 5 * \mathrm{E} \\
& +\beta 6 * \mathrm{~F}
\end{aligned}
$$

\section{Results}

\section{Characteristics of the Participants}

Basic characteristics of the study population are summarized in Table 1. Overall, the COPD participants had higher proportion of current and ex-smokers than the non-COPD participants. Participants with COPD also had higher proportion of co-morbidities including diabetes mellitus, hyperlipidemia, hypertension and anemia than the participants without COPD.

\section{Hand-Grip Strength in COPD}

Since hand-grip strength is influenced by age, ${ }^{26}$ smoking status, ${ }^{11}$ waist circumference, ${ }^{27}$ anemia, ${ }^{28}$ hypertension ${ }^{29}$ and serum HDL-C levels, ${ }^{30}$ so we performed multivariable analysis to adjust for these factors. Among men, the adjusted hand-grip strength was $45.23 \pm 4.11$ for nonCOPD group, $43.21 \pm 3.71$ for GOLD-1 subgroup, 41.88 \pm 2.81 for GOLD-2 subgroup and $39.45 \pm 3.75$ for GOLD-3 and 4 subgroups (Figure 1A). Among women, the adjusted hand-grip strength was $30.31 \pm 2.63$ for non-COPD group, $29.01 \pm 2.32$ for GOLD-1 subgroup, $25.42 \pm 2.41$ for GOLD -2 subgroup and $23.82 \pm 2.15$ for GOLD-3 and 4 subgroups. Men had higher adjusted hand-grip strength $(\mathrm{p}<$ 0.05 ) than women among the non-COPD participants and three subgroups of COPD patients. Within the same gender, participants with GOLD-3 and 4 stages showed lesser adjusted hand-grip strength than the non-COPD participants among both men $(39.45 \pm 3.75$ vs. $45.23 \pm 4.11$; $\mathrm{p}<$ $0.05)$ and women $(23.82 \pm 2.15$ vs $30.31 \pm 2.63 ; \mathrm{p}<0.05)$ participants (Figure 1A). Further, among women participants, those with GOLD-2 stage also had lower adjusted hand-grip strength than the non-COPD group $(25.42 \pm 2.41$ vs $30.31 \pm 2.63 ; \mathrm{p}<0.05$ ) (Figure 1B). 
Table I Baseline Characteristics of the Study Participants

\begin{tabular}{|c|c|c|c|c|c|c|c|c|}
\hline & \multicolumn{4}{|l|}{ Men } & \multicolumn{4}{|l|}{ Women } \\
\hline & $\begin{array}{l}\text { Non- } \\
\text { COPD }\end{array}$ & GOLD-I & $\begin{array}{l}\text { COPD } \\
\text { GOLD-2 }\end{array}$ & $\begin{array}{l}\text { GOLD-3 } \\
\text { and } 4\end{array}$ & $\begin{array}{l}\text { Non- } \\
\text { COPD }\end{array}$ & GOLD - I & $\begin{array}{l}\text { COPD } \\
\text { GOLD-2 }\end{array}$ & $\begin{array}{l}\text { GOLD-3 } \\
\text { and } 4\end{array}$ \\
\hline \multicolumn{9}{|l|}{ Age category (years) } \\
\hline 56-65, n (\%) & $212(56.6)$ & $115(52.7)$ & $58(47.9)$ & $12(50)$ & $227(54.8)$ & $132(52.5)$ & 71 (47.6) & $17(54.8)$ \\
\hline $66-75, \mathrm{n}(\%)$ & $162(43.4)$ & $103(47.3)$ & $63(52.1)$ & $12(50)$ & $187(45.2)$ & $119(47.5)$ & $78(52.4)$ & 14 (45.2) \\
\hline \multicolumn{9}{|l|}{ Smoking status } \\
\hline Non-smokers, n (\%) & $103(27.5)$ & $34(15.6)$ & $17(14.1)$ & $4(16.6)$ & $403(97.3)$ & $236(94)$ & 146 (98) & $29(93.5)$ \\
\hline Ex-smoker, n (\%) & $182(48.6)$ & $57(26.1)$ & $41(33.8)$ & $13(54.1)$ & $7(1.7)$ & II (4.4) & $2(1.3)$ & I (3.2) \\
\hline Current, n (\%) & $89(23.8)$ & $127(58.2)$ & $63(52.1)$ & $7(29.1)$ & $4(0.9)$ & $4(1.6)$ & $\mathrm{I}(0.7)$ & $\mathrm{I}(3.2)$ \\
\hline BMI $\left(K g / m^{2}\right)($ Mean $\pm S D)$ & $24.3 \pm 2.3$ & $24.1 \pm 3.4$ & $23.8 \pm 2$ & $24 \pm 3.3$ & $25.1 \pm 3.8$ & $24.5 \pm 2.1$ & $24.8 \pm 2.7$ & $24.4 \pm 3.3$ \\
\hline $\begin{array}{l}\text { Waist Circum. (cm) (Mean } \pm \\
\text { SD) }\end{array}$ & $85.3 \pm 9.3$ & $84.2 \pm 8.3$ & $83.3 \pm 10$ & $84.3 \pm 4.3$ & $87.3 \pm 5.3$ & $84.1 \pm 7.3$ & $84.7 \pm 6.3$ & $83.9 \pm 9.3$ \\
\hline FEVI (L) (Mean \pm SD) & $2.78 \pm 0.5$ & $2.24 \pm 0.6$ & $1.66 \pm 0.4$ & $1.36 \pm 0.3$ & $2.75 \pm 0.4$ & $2.2 \pm 0.4$ & $1.59 \pm 0.3$ & $1.26 \pm 0.3$ \\
\hline $\begin{array}{l}\mathrm{FEV}, \% \text { predicted (Mean } \pm \\
\mathrm{SD} \text { ) }\end{array}$ & $97.2 \pm 4.4$ & $78.5 \pm 7.3$ & $58.3 \pm 8.8$ & $47.6 \pm 8.1$ & $98.5 \pm 3.6$ & $79.1 \pm 6.2$ & $57 \pm 9.3$ & $45.3 \pm 6.1$ \\
\hline Diabetes, n (\%) & $16(4.4)$ & $13(5.9)$ & $15(12.4)$ & $5(20.8)$ & $13(3.8)$ & $17(6.7)$ & $16(10.7)$ & $5(16.1)$ \\
\hline Dyslipidemia, n (\%) & $61(16.3)$ & $37(16.9)$ & $31(25.6)$ & $9(37.5)$ & $44(10.6)$ & $39(15.5)$ & $36(24.1)$ & $9(29)$ \\
\hline Hypertension, n (\%) & $17(4.5)$ & $22(10.1)$ & $12(9.9)$ & $4(16.6)$ & II (2.6) & $23(9.1)$ & $19(12.7)$ & $4(12.9)$ \\
\hline Anemia, n (\%) & $36(9.6)$ & $42(19.2)$ & $29(23.9)$ & $8(33.3)$ & $53(12.8)$ & $34(13.5)$ & $27(18.1)$ & $10(32.2)$ \\
\hline
\end{tabular}

Only women participants showed significant association between $\mathrm{FEV}_{1} \%$ and adjusted hand-grip strength $\left(\mathrm{r}^{2}=0.005, \mathrm{p}<0.05\right)$ while the association between $\mathrm{FEV}_{1} \%$ and adjusted hand-grip strength failed to reach statistical significance in men $\left(r^{2}=0.001, p<0.333\right)$ (Figure 1B).

\section{Effects of Smoking Status on Hand-Grip Strength}

Reduced hand-grip strength has been associated with smoking in different age groups. ${ }^{11}$ To determine whether smoking affects hand-grip strength in the COPD participants, we measured hand-grip strength in the active, exand current smokers with COPD and adjusted it for covariants. Among men, current smokers had lower handgrip strength than the non-smokers of same age groups, as shown among the 55-65 years $(41.27 \pm 3.87$ vs $44.65 \pm$ $3.56 ; p<0.05)$ and $66-75$ years old $(37.47 \pm 4.21$ vs 41.35 $\pm 4.32 ; p<0.05$ ) participants (Figure $2 \mathrm{~A}$ ). Among ex- and current smokers, 55-65 years old men had higher handgrip strength than the 66-75 years old men (ex-smokers; $43.42 \pm 4.32$ vs $39.62 \pm 3.51 ; p<0.05$, current smokers; $(41.27 \pm 3.87$ vs $37.47 \pm 4.21 ; p<0.05)$. Statistical analysis was not conducted on female participants due to smaller sample size of ex- and current smokers.

\section{Relationship of Hand-Grip Strength and FEV,$\%$ with Serum HDL-C}

An association of hand-grip strength and $\mathrm{FEV}_{1} \%$ with the serum metabolic parameters has been reported before. ${ }^{10} \mathrm{In}$ accordance with those findings, a significant association was found between the adjusted hand-grip strength and serum HDL-C in the male $\left(\mathrm{r}^{2}=0.121, \mathrm{p}<0.05\right)$ and female $\left(r^{2}=0.085, p<0.05\right)$ participants (Figure $2 \mathrm{~B}$ ). Serum HDL-C was also correlated to the $\mathrm{FEV}_{1} \%$ in the male $\left(r^{2}=0.113, p<0.05\right)$ and female $\left(r^{2}=0.175\right.$, $\mathrm{p}<0.05$ ) populations (Figure $2 \mathrm{C}$ ).

\section{Relationship of Hand-Grip Strength and FEV $1 \%$ with EQ-5D Score}

Deterioration of health-related quality of life as assessed by EQ-5D score is generally associated with lower hand-grip strength. ${ }^{31}$ In agreement with those findings, we report lower adjusted hand-grip strength in men and women participants with lower E1-5D score (Table 2). Participants with lower adjusted hand-grip strength and lower $\mathrm{FEV}_{1} \%$ had problems with mobility, self-care, usual activities, pain/discomfort, anxiety/depression than the participants with higher EQ-5D scores (Table 2). 

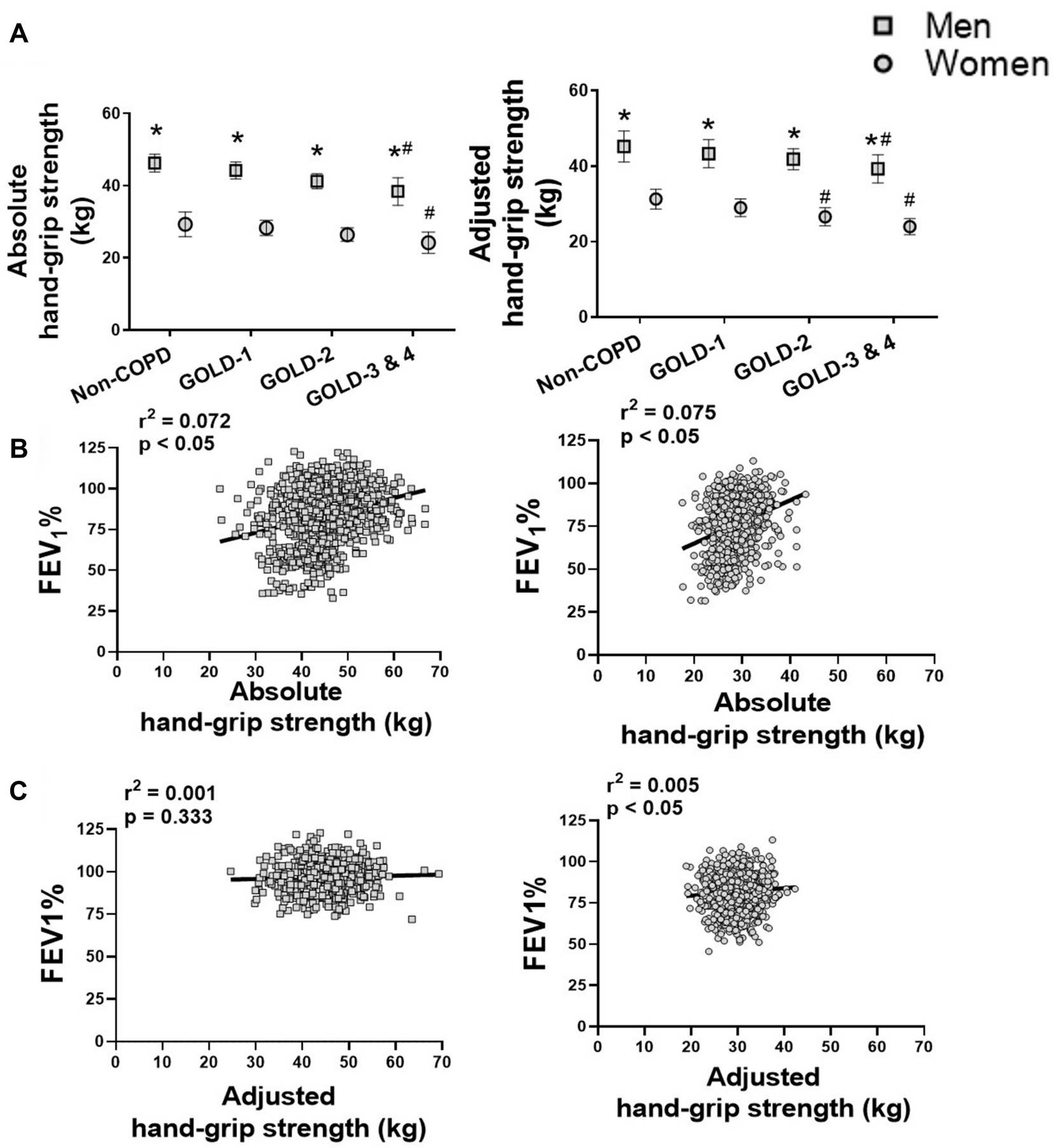

Figure I (A) Absolute and adjusted hand-grip strength for age, smoking status, waist circumference, anemia, hypertension and serum HDL-C in subjects with non-COPD and COPD by GOLD grades. Values are expressed as mean \pm SD; one-way analysis of variance. ${ }^{*} \mathrm{P}<0.05$ vs women participants of the same group, ${ }^{\#} \mathrm{P}<0.05$ vs non-COPD participants of the same gender. Relationship of the $\mathrm{FEV}_{1} \%$ with the absolute (B) and adjusted hand-grip strength (C) in the men and women participants with and without COPD.

Serum Biomarkers, Hand-Grip Strength and $\mathrm{FEV}, \%$

Among men, adjusted hand-grip strength was significantly correlated with TSA $\left(\mathrm{r}^{2}=0.104, \mathrm{p}<0.05\right)$ (Figure $\left.3 \mathrm{~A}\right)$ but not with AGP $\left(\mathrm{r}^{2}=0.036, \mathrm{p}=0.155\right)$ (Figure $3 \mathrm{C}$ ) and

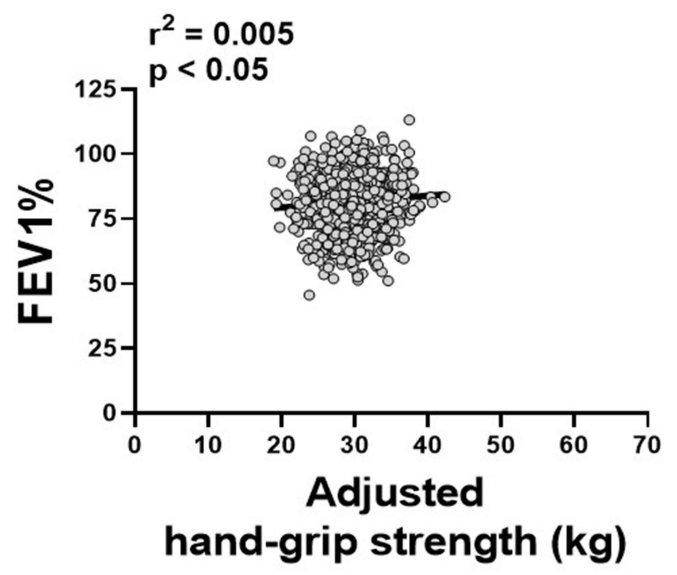

$\mathrm{CC} 16\left(\mathrm{r}^{2}=0.035, \mathrm{p}=0.188\right)$ (Figure 3E). Among women, only CC16 showed significant correlation with adjusted hand-grip strength $\left(\mathrm{r}^{2}=0.198, \mathrm{p}<0.05\right)$ (Figure 3E) while of TSA $\left(r^{2}=0.039, p=0.125\right)$ (Figure $3 \mathrm{~A}$ ) and AGP $\left(r^{2}=0.002, p=0.689\right)$ (Figure $3 C$ ) did not show 

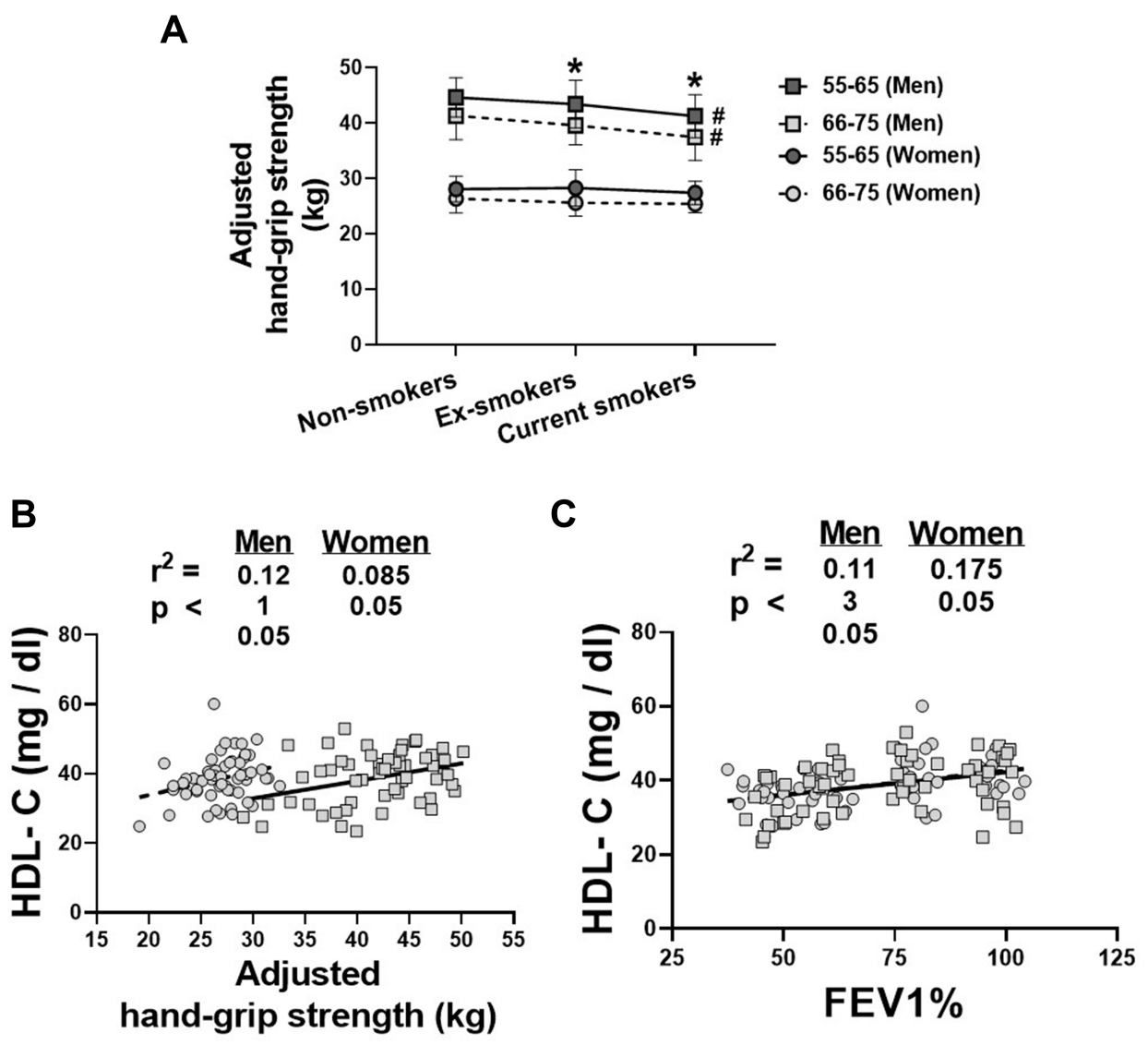

Figure 2 (A) Hand-grip strength according to smoking status in the men and women participants of different age groups; Values are expressed as mean \pm SD; one-way analysis of variance. ${ }^{*} \mathrm{P}<0.05$ vs $66-75$ old participants of the same gender, ${ }^{*} \mathrm{P}<0.05$ vs non-smokers of the same gender and age group. (B) relationship of the serum HDL-C with the hand-grip strength and (C) FEV $\%$ in men and women participants of the non-COPD and COPD groups. Hand-grip strength was adjusted for age, smoking status, waist circumference, anemia and hypertension in all analyses.

statistically significant correlations with adjusted handgrip strength. TSA and CC16 were also strong predictors of $\mathrm{FEV}_{1} \%$ in men $\left(\mathrm{TSA} ; \mathrm{r}^{2}=0.176, \mathrm{p}<0.05, \mathrm{CC} 16 ; \mathrm{r}^{2}=\right.$ $0.519, \mathrm{p}<0.05)$ and women (TSA; $\mathrm{r}^{2}=0.112, \mathrm{p}<0.05$, CC16; $\left.\mathrm{r}^{2}=0.569, \mathrm{p}<0.05\right)$ participants with COPD (Figure 3B and F). On the other hand, AGP was a poor predictor of $\mathrm{FEV}_{1} \%$ in both genders although it showed moderate correlation with $\mathrm{FEV}_{1} \%$ in men $\left(\mathrm{r}^{2}=0.055, \mathrm{p}=\right.$ 0.072) (Figure 3D), which failed to reach statistical significance. In a group-wise analysis, serum TSA levels were elevated among participants with GOLD-3 and 4 (Men; $\approx 16.9 \%, \mathrm{p}<0.05$, Women; $\approx 11.5 \%$, p $<0.05$ ) but not GOLD-1 or 2, when compared to non-COPD control group (Table 3). Similarly, serum CC16 levels were reduced among participants with GOLD-2 (Men; $\approx 29 \%$, $\mathrm{p}<0.05$, Women; $\approx 29.6 \%, \mathrm{p}<0.05)$ and stages 3 and 4 combined (Men; $\approx 48 \%, \mathrm{p}<0.05$, Women; $\approx 38.6 \%$, p $<$ $0.05)$, when compared to non-COPD control group. On the other hand, a significant change in the serum AGP levels was only found in the men with GOLD-3 and 4 stages when compared to the participants with GOLD-1 ( $\approx 29 \%$, $\mathrm{p}<0.05)$. Serum AGP levels in the women did not change among non-COPD participants and the three subgroups of COPD patients (Table 3 ).

\section{Discussion}

We report in this population-based cross-sectional study that: (1) a potential association exists between the circulating levels of CC16 and TSA and clinical variables of pulmonary $\left(\mathrm{FEV}_{1} \%\right)$ and muscle weakness in patients with COPD. (2) hand-grip strength has an association with spirometry and quality of life as participants with low $\mathrm{FEV}_{1} \%$ and low scores on mobility, self-care, usual activities, pain/discomfort and anxiety/depression consistently had lower hand-grip strength than the healthy controls.

Several groups have evaluated potential candidate biomarkers of COPD as a tool to monitor disease severity, suggesting that it might be possible to characterize 
Table 2 Classification of the COPD Participants According to EQ-5D Scores and Association with Hand-Grip Strength and FEV,\%

\begin{tabular}{|c|c|c|c|c|c|c|}
\hline \multirow{2}{*}{$\begin{array}{l}\text { EQ-5D Descriptive } \\
\text { Scores }\end{array}$} & \multicolumn{3}{|l|}{ Men } & \multicolumn{3}{|l|}{ Women } \\
\hline & N (\%) & $\begin{array}{l}\text { Absolute Hand-Grip } \\
\text { Strength }(\mathrm{kg}) \text { (Mean } \pm \text { SD) }\end{array}$ & $\begin{array}{l}\text { FEVI\% } \\
\text { (Mean } \pm \text { SD) }\end{array}$ & N (\%) & $\begin{array}{l}\text { Absolute Hand-Grip } \\
\text { Strength }(k g)(\text { Mean } \pm \text { SD) }\end{array}$ & $\begin{array}{l}\text { FEVI\% } \\
\text { (Mean } \pm \text { SD) }\end{array}$ \\
\hline $\begin{array}{l}\text { Mobility } \\
\text { No problem } \\
\text { Some problem } \\
\text { Extreme problem }\end{array}$ & $\begin{array}{l}221(66.9) \\
87(26.3) \\
22(6.6)\end{array}$ & $\begin{array}{l}47.2 \pm 5.2 \\
43.7 \pm 3.3^{*} \\
37.1 \pm 3.9 *, \#\end{array}$ & $\begin{array}{l}82.3 \pm 9.3 \\
61.6 \pm 5.3^{*} \\
43.2 \pm 7.7^{*}, \#\end{array}$ & $\begin{array}{l}209(61.3) \\
81(23.7) \\
51(15)\end{array}$ & $\begin{array}{l}31.8 \pm 3.4 \\
26.4 \pm 4.1^{*} \\
24.8 \pm 3.3^{*}\end{array}$ & $\begin{array}{l}79.2 \pm 6.6 \\
58.5 \pm 5.4 * \\
48.6 \pm 4.7 * \#\end{array}$ \\
\hline $\begin{array}{l}\text { Self-care } \\
\text { No problem } \\
\text { Some problem } \\
\text { Extreme problem }\end{array}$ & $\begin{array}{l}25 \mid(76.1) \\
65(19.7) \\
14(4.2)\end{array}$ & $\begin{array}{l}49 \pm 4.6 \\
42.2 \pm 2.8^{*} \\
36.1 \pm 3.3^{*, \#}\end{array}$ & $\begin{array}{l}77.2 \pm 7.3 \\
65.9 \pm 5.6^{*} \\
46.7 \pm 6.3^{*}, \#\end{array}$ & $\begin{array}{l}268(78.9) \\
54(15.8) \\
19(5.6)\end{array}$ & $\begin{array}{l}29.2 \pm 3.3 \\
26.3 \pm 3.9 * \\
25.1 \pm 5.3 *\end{array}$ & $\begin{array}{l}75.6 \pm 4.7 \\
60.4 \pm 4.2^{*} \\
45.2 \pm 3.3^{*}, \#\end{array}$ \\
\hline $\begin{array}{l}\text { Usual activities } \\
\text { No problem } \\
\text { Some problem } \\
\text { Extreme problem }\end{array}$ & $\begin{array}{l}189(57.3) \\
103(3 \mid .2) \\
38(11.5)\end{array}$ & $\begin{array}{l}48.6 \pm 4.4 \\
43.7 \pm 5.1 * \\
39.2 \pm 3.9 *\end{array}$ & $\begin{array}{l}79.1 \pm 8.3 \\
59 \pm 4.4^{*} \\
48.4 \pm 5.1^{* \# \#}\end{array}$ & $\begin{array}{l}257(75.4) \\
63(18.5) \\
21(6.1)\end{array}$ & $\begin{array}{l}30.3 \pm 3.8 \\
27.1 \pm 5.3^{*} \\
23.9 \pm 4.3^{*, \#}\end{array}$ & $\begin{array}{l}83.2 \pm 6.5 \\
61.7 \pm 4.7^{*} \\
47.2 \pm 5.3^{*}, \#\end{array}$ \\
\hline $\begin{array}{l}\text { Pain/discomfort } \\
\text { No problem } \\
\text { Some problem } \\
\text { Extreme problem }\end{array}$ & $\begin{array}{l}237(71.8) \\
61(18.5) \\
32(9.7)\end{array}$ & $\begin{array}{l}48.9 \pm 6.3 \\
42.2 \pm 5.2 * \\
38.6 \pm 4.9 *\end{array}$ & $\begin{array}{l}79.5 \pm 7.1 \\
61.2 \pm 5.3^{*} \\
52.4 \pm 6.3^{*, \#}\end{array}$ & $\begin{array}{l}197(57.7) \\
105(30.8) \\
39(11.4)\end{array}$ & $\begin{array}{l}31.1 \pm 4.3 \\
27.9 \pm 3.3^{*} \\
24.1 \pm 4.3^{*}, \#\end{array}$ & $\begin{array}{l}76.3 \pm 6.4 \\
59 \pm 5.3^{*} \\
50.1 \pm 5^{*} \#\end{array}$ \\
\hline $\begin{array}{l}\text { Anxiety/depression } \\
\text { No problem } \\
\text { Some problem } \\
\text { Extreme problem }\end{array}$ & $\begin{array}{l}203(6 \mid .5) \\
109(33) \\
18(5.4)\end{array}$ & $\begin{array}{l}47.7 \pm 4.8 \\
41.6 \pm 4.9 * \\
35.7 \pm 5.5^{*}\end{array}$ & $\begin{array}{l}81.4 \pm 6.2 \\
59.2 \pm 4.3^{*} \\
49.6 \pm 4.3^{*}, \#\end{array}$ & $\begin{array}{l}235(68.9) \\
73(21.4) \\
23(6.7)\end{array}$ & $\begin{array}{l}32.2 \pm 5.3 \\
27.9 \pm 3.6^{*} \\
22.6 \pm 4.3^{*, \#}\end{array}$ & $\begin{array}{l}79.1 \pm 6.9 \\
62.8 \pm 4.3^{*} \\
46.7 \pm 3.5^{*}, \#\end{array}$ \\
\hline
\end{tabular}

Notes: Values are Expressed as Mean \pm SD; One-Way Analysis of Variance. * $p<0.05$ Vs Subgroup with "no Problem" of the Same EQ-5D Parameter of the Same Gender, \# $p<0.05$ Vs Subgroup with "some Problem" of the Same EQ-5D Parameter in the Same Gender.

COPD using systemic biomarkers. ${ }^{32}$ However, the association of circulating biomarkers with muscle weakness in multi-systemic COPD is poorly characterized. Furthermore, the heterogeneity of COPD phenotype makes it difficult to draw definite conclusions from studies involving small sample size. Here, we investigated the biomarkers for decline in lung function and muscle weakness in patients with COPD, which will help to assess diseases progression during hospitalization and recovery stages of COPD.

Using a large sample size with considerable representation of patients with various stages of COPD, we have shown potential coupling of serum $\mathrm{CC} 16$ and TSA with $\mathrm{FEV}_{1} \%$ and hand-grip strength in COPD. The positive correlation between serum $\mathrm{CC} 16$ and $\mathrm{FEV}_{1} \%$ has been reported earlier. ${ }^{33}$ Here, we have extended it to include hand-grip strength, at least in advanced stages of COPD. CC16 has anti-inflammatory and anti-toxicant effects in lungs $^{14}$ and may protect against spirometry decline in COPD. The positive association between CC16 and handgrip strength reported in this study is probably because of anti-inflammatory properties of $\mathrm{CC} 16$, since systemic inflammation is known to reduce hand-grip strength. ${ }^{34} \mathrm{We}$ also found an association of serum TSA with $\mathrm{FEV}_{1} \%$ and hand-grip strength. TSA is a marker of inflammation and its serum levels are elevated in systemic inflammation associated with COPD ${ }^{16}$ and sarcopenia. ${ }^{35}$ However, to the best of our knowledge, no study has investigated the association between TSA and hand-grip strength in patients with COPD. In this study, we show the potential coupling of serum TSA with $\mathrm{FEV}_{1} \%$ and hand-grip strength in the participants with GOLD-2 and GOLD-3 and 4 who show significant weakness of hand-grip muscles.

The relationship between hand-grip strength and spirometry performance in patients with COPD is still controversial as an unchanged ${ }^{6,36}$ or reduced $^{37,38}$ hand-grip strength has been reported with reduction in $\mathrm{FEV}_{1} \%$ in the COPD patients. This discrepancy is partly due to multiple factors including co-morbidities and inclusion of participants mainly with mild to moderate degree of COPD (GOLD-1 and 2 stages) in whom COPD may not be severe enough to trigger muscle weakness. Diabetes 

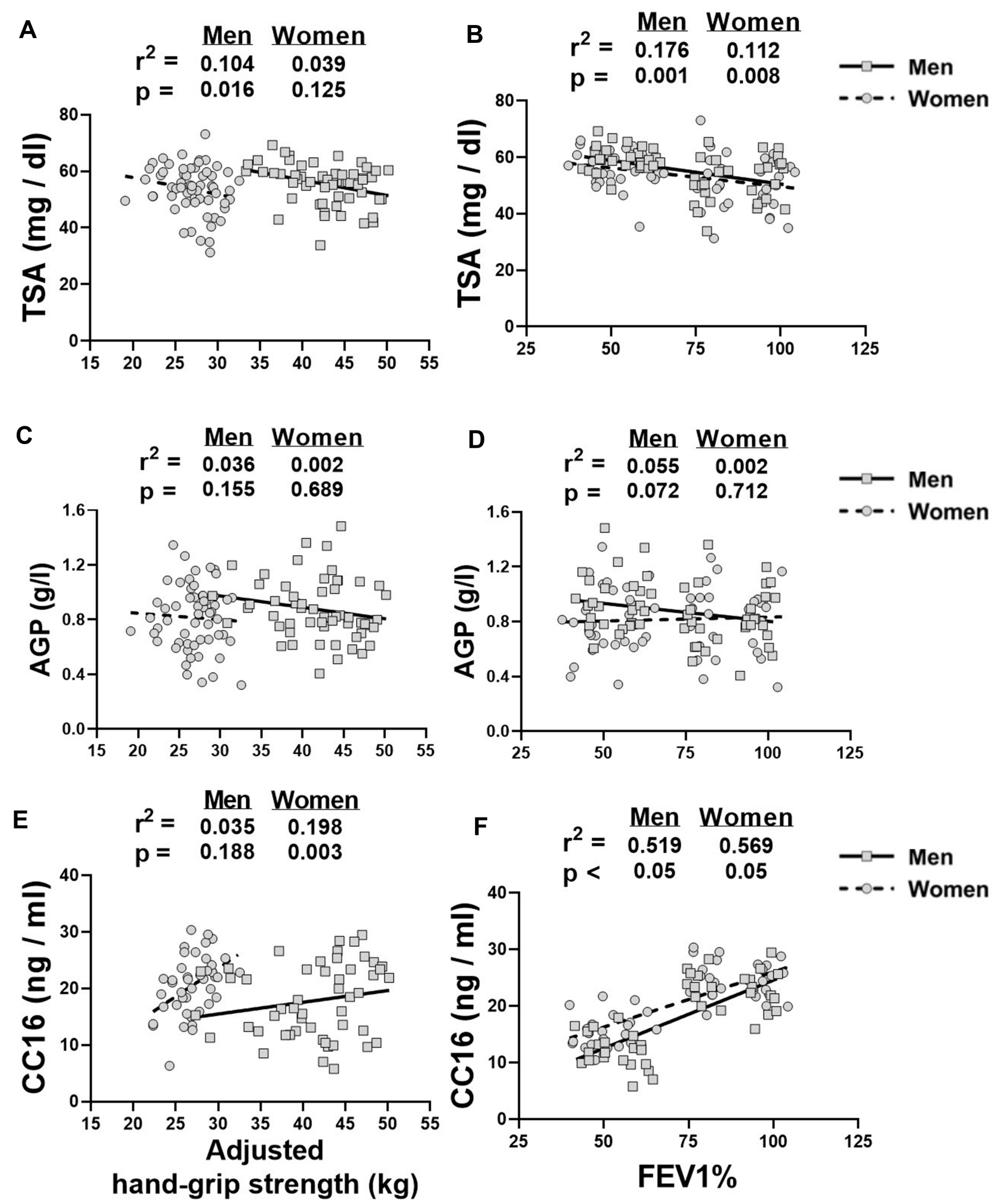

Figure 3 Linear regression graphs of the hand-grip strength and FEV $\%$ with serum biomarkers of TSA (A, B), AGP (C, D) and CCI6 (E, F) in the men and women participants with and without COPD. Hand-grip strength was adjusted for age, smoking status, waist circumference, anemia and hypertension in all analyses.

and hypertension have significant detrimental effects on muscle strength, which at least partly is due to increased secretion of inflammatory cytokines, motor neuropathy, elevated oxidative stress and lifestyle modifications. A small fraction of our healthy controls and patients with COPD had diabetes and hypertension. However, hand-grip 
Table 3 Protein Expression of the Serum Biomarkers of TSA, AGP, CCI6 and HDL-C in the Sera of Participants with and Without COPD

\begin{tabular}{|l|l|l|l|l|l|l|l|l|}
\hline & \multicolumn{3}{|l}{ Men } & \multicolumn{2}{l|}{ Women } \\
\cline { 2 - 9 } & Non-COPD & GOLD-I & COPD GOLD-2 & GOLD-3 and 4 & Non-COPD & GOLD-I & COPD GOLD-2 & GOLD-3 and 4 \\
\hline TSA (mg/dl) & $51.4 \pm 3.6$ & $52.5 \pm 2.1$ & $57.4 \pm 3.8^{*, \#}$ & $60.1 \pm 3.4^{*, \#}$ & $51.1 \pm 3.1$ & $51.6 \pm 2.6$ & $55 \pm 3.8^{*, \#}$ & $57 \pm 3.3^{*, \#}$ \\
AGP $(\mathrm{g} / \mathrm{l})>$ & $0.794 \pm 0.04$ & $0.743 \pm 0.07$ & $0.936 \pm 0.04$ & $0.963 \pm 0.05^{\#}$ & $0.813 \pm 0.05$ & $0.846 \pm 0.07$ & $0.833 \pm 0.06$ & $0.783 \pm 0.05$ \\
CCl6 $(\mathrm{ng} / \mathrm{mL})$ & $23.53 \pm 3.2$ & $21.66 \pm 4.13$ & $16.7 \pm 3.51^{*, \#}$ & $12.05 \pm 2.09^{*, \#}$ & $24.68 \pm 4.06$ & $21.33 \pm 3.71$ & $17.36 \pm 2.82^{*, \#}$ & $15.15 \pm 2.94^{*, \#}$ \\
HDL-C $(\mathrm{mg} / \mathrm{dl})$ & $42.92 \pm 2.34$ & $41.96 \pm 1.97$ & $39.36 \pm 3.46$ & $31.71 \pm 3.65^{*, \#, 4}$ & $41.68 \pm 3.18$ & $40.27 \pm 3.21$ & $37.26 \pm 2.14$ & $34.21 \pm 3.24^{*, \#}$ \\
\hline
\end{tabular}

Notes: Values are Expressed as Mean \pm SD; One-Way Analysis of Variance. ${ }^{*} \mathrm{p}<0.05$ Vs Non-COPD Group of the Same Gender; ${ }^{*} \mathrm{p}<0.05$ Vs GOLD-I Subgroup of the Same Gender; ${ }^{\varphi} \mathrm{p}<0.05$ Vs GOLD-2 Subgroup of the Same Gender.

strength was adjusted for these co-morbidities before the final analysis. Since the participants in each GOLD stage had a huge variation in the $\mathrm{FEV}_{1} \%$ values, we hypothesized that the $\mathrm{FEV}_{1} \%$ as a continuous variable might be a better predictor of hand-grip strength when evaluating disease severity in COPD. In support of this, we report an association between $\mathrm{FEV}_{1} \%$ and hand-grip strength in the COPD participants so that the reduced $\mathrm{FEV}_{1} \%$ was associated with lower hand-grip strength irrespective of GOLD stage. However, this coupling persisted only in women but not in men, when hand-grip strength was adjusted for confounders. Gender differences in the pulmonary function have been described before as women tend to have slightly higher $\mathrm{FEV}_{1} \%$ than men in reproductive age. ${ }^{39}$ However, menopause is associated with an accelerated decline in lung functions ${ }^{40}$ and muscle strength ${ }^{41}$ because of low levels of estrogen and progesterone. Thus, menopause might have contributed to stronger coupling between $\mathrm{FEV}_{1} \%$ and hand-grip strength in women. Moreover, most of the women in our study were nonsmokers, so additive negative effect of smoking on handgrip strength was restricted to men only. Thus, after adjustment for this effect, the adjusted hand-grip strength did not show significant correlation with $\mathrm{FEV}_{1} \%$ in men, unlike in women. Thus, the reproductive aging and absence of smoking might have contributed to the stronger association between $\mathrm{FEV}_{1} \%$ and hand-grip strength in women, when compared to men.

Poor scores on mobility, anxiety, pain, discomfort and depression were consistently associated with reduced hand-grip strength in men and women with COPD. These findings are consistent with earlier reports ${ }^{31}$ and suggest that hand-grip strength can be used as a physical biomarker of the quality of life. Given that a direct coupling between health-related quality of life and disease severity in COPD participants has been proposed before, ${ }^{42}$ measurement of quality of life in the COPD participants may be a useful tool to assess pulmonary decline and muscle weakness in COPD.

In terms of smoking affecting hand-grip strength, ${ }^{11}$ reduced hand-grip strength in the male smokers is probably attributed to lung dysfunction as a significant direct effect of smoking on hand-grip strength in COPD is not well elucidated. ${ }^{43}$ On the other hand, the relation between reduced HDL-C and reduced hand-grip strength has been described before in a list of diseases, ${ }^{10,30}$ which we expand to include COPD here.

A very large sample size and careful clinical, biochemical and functional characterization are the strengths of this study. However, there are several potential limitations. First, it was a cross-sectional study so we could not assess longitudinal changes in the hand-grip strength and serum biomarkers in relation to disease exacerbation and/or response to therapies. Second, we could not perform limbs' girth measurements and/or radiography (measures of muscle atrophy) and walk tests (functional measures of cardiopulmonary fitness); and hence could not analyze their correlations with hand-grip strength and serum biomarkers. Third, we could not perform computed tomography analysis of body composition and airways thickness which are recently shown to affect hand-grip strength independent of COPD. ${ }^{44}$ Fourth, the number of participants with GOLD stages-3 and 4 in our study was much smaller than those with COPD stages 1 and 2, so caution should be exercised while interpreting the results. These proportions, nevertheless, represent the prevalence of COPD in the general population. Fifth, the number of smokers among women was very small for statistical analysis so our analysis on the correlation between smoking and hand-grip strength is restricted to men only. 
In summary, we have shown that expressions of serum CC16 and TSA have positive associations with $\mathrm{FEV}_{1} \%$ and hand-grip strength in COPD. Smoking and lower serum HDL-C exacerbate the compromised muscle and lung functions in these patients. Further studies are required to establish the efficacy of serum CC16 and TSA for monitoring disease progression in COPD.

\section{Data Sharing Statement}

Raw data from the patient cohorts cannot be shared due to the privacy policies of the university hospitals from where data were collected.

\section{Acknowledgment}

This work was supported by Seed grants from the University of Sharjah to Rizwan Qaisar (1901090146) and Asima Karim (1901090149). We are thankful to Maria Aziz and Jawad Ahmad for helping with data collection, Faisal Nadeem and Ahmad Hassan Nadeem for helping with data analysis.

\section{Disclosure}

The authors declare that they have no conflicts of interest in this work.

\section{References}

1. Huertas A, Palange P. COPD: a multifactorial systemic disease. Ther Adv Respir Dis. 2011;5:217-224. doi:10.1177/1753465811400490

2. Wust RC, Degens H. Factors contributing to muscle wasting and dysfunction in COPD patients. Int J Chron Obstruct Pulmon Dis. 2007;2:289-300.

3. Gosselink R, Troosters T, Decramer M. Distribution of muscle weakness in patients with stable chronic obstructive pulmonary disease. J Cardiopulm Rehabil. 2000;20:353-360. doi:10.1097/00008483-200011000-00004

4. Swallow EB, Reyes D, Hopkinson NS, et al. Quadriceps strength predicts mortality in patients with moderate to severe chronic obstructive pulmonary disease. Thorax. 2007;62:115-120. doi:10.1136/thx.2006.062026

5. Leong DP, Teo KK, Rangarajan S, et al. Prognostic value of grip strength: findings from the Prospective Urban Rural Epidemiology (PURE) study. Lancet. 2015;386:266-273. doi:10.1016/S0140-6736(14)62000-6

6. Jeong M, Kang HK, Song P, et al. Hand grip strength in patients with chronic obstructive pulmonary disease. Int J Chron Obstruct Pulmon Dis. 2017;12:2385-2390. doi:10.2147/COPD.S140915

7. Lee SH, Kim SJ, Han Y, et al. Hand grip strength and chronic obstructive pulmonary disease in Korea: an analysis in KNHANES VI. Int J Chron Obstruct Pulmon Dis. 2017;12:2313-2321. doi:10.21 47/COPD.S142621

8. Calik-Kutukcu E, Savci S, Saglam M, et al. A comparison of muscle strength and endurance, exercise capacity, fatigue perception and quality of life in patients with chronic obstructive pulmonary disease and healthy subjects: a cross-sectional study. BMC Pulm Med. 2014;14:6. doi:10.1186/1471-2466-14-6

9. Lad UP, Satyanarayana P, Shisode-Lad S, Siri Ch C, Kumari NR. A study on the correlation between the Body Mass Index (BMI), the body fat percentage, the handgrip strength and the handgrip endurance in underweight, normal weight and overweight adolescents. $J$ Clin Diagn Res. 2013;7:51-54. doi:10.7860/JCDR/2012/5026.2668
10. Li D, Guo G, Xia L, et al. Relative handgrip strength is inversely associated with metabolic profile and metabolic disease in the general population in China. Front Physiol. 2018;9:59. doi:10.3389/ fphys.2018.00059

11. Al-Obaidi S, Al-Sayegh N, Nadar M. Smoking impact on grip strength and fatigue resistance: implications for exercise and hand therapy practice. $J$ Phys Act Health. 2014;11:1025-1031. doi:10.112 3/jpah.2011-0357

12. Ghosh B. Serum biomarkers of COPD. Respir Care. 2016;61:395. doi: $10.4187 /$ respcare. 04592

13. Kawamatawong T, Apiwattanaporn A, Siricharoonwong W. Serum inflammatory biomarkers and clinical outcomes of COPD exacerbation caused by different pathogens. Int J Chron Obstruct Pulmon Dis. 2017;12:1625-1630. doi:10.2147/COPD.S132132

14. Laucho-Contreras ME, Polverino F, Gupta K, et al. Protective role for club cell secretory protein-16 (CC16) in the development of COPD. Eur Respir J. 2015;45:1544-1556. doi:10.1183/09031936. 00134214

15. Engstrom G, Segelstorm N, Ekberg-Aronsson M, et al. Plasma markers of inflammation and incidence of hospitalisations for COPD: results from a population-based cohort study. Thorax. 2009;64:21 1-215. doi:10.1136/thx.2008.102079

16. Rajendiran KS, Ananthanarayanan RH, Satheesh S, Rajappa M. Elevated levels of serum sialic acid and high-sensitivity C-reactive protein: markers of systemic inflammation in patients with chronic heart failure. Br J Biomed Sci. 2014;71:29-32. doi:10.1080/096748 45.2014.11669959

17. Rodrigues FM, Demeyer H, Loeckx M, et al. Health status deterioration in subjects with mild to moderate airflow obstruction, a six years observational study. Respir Res. 2019;20:93. doi:10.1186/s12931019-1061-7

18. Pickard AS, Wilke C, Jung E, et al. Use of a preference-based measure of health (EQ-5D) in COPD and asthma. Respir Med. 2008;102:519-536. doi:10.1016/j.rmed.2007.11.016

19. World Medical A. World medical association declaration of Helsinki: ethical principles for medical research involving human subjects. JAMA. 2013;310:2191-2194. doi:10.1001/jama.2013.281053

20. Mirza S, Clay RD, Koslow MA, Scanlon PD. COPD guidelines: a review of the 2018 GOLD report. Mayo Clin Proc. 2018;93:1488-1502. doi:10.1016/j.mayocp.2018.05.026

21. National Collaborating Centre for Chronic, C. Chronic obstructive pulmonary disease. National clinical guideline on management of chronic obstructive pulmonary disease in adults in primary and secondary care. Thorax. 2004;59(Suppl 1):1-232.

22. Culver BH, Graham BL, Coates AL, et al. Recommendations for a standardized pulmonary function report. An official American thoracic society technical statement. Am J Respir Crit Care Med. 2017;196:1463-1472. doi:10.1164/rccm.201710-1981ST

23. Zaigham S, Johnson L, Wollmer P, Engstrom G. Measures of low lung function and the prediction of incident COPD events and acute coronary events. Respir Med. 2018;144:68-73. doi:10.1016/j.rmed.20 18.10.007

24. Safka KA, Wald J, Wang H, McIvor L, McIvor A. GOLD stage and treatment in COPD: a 500 patient point prevalence study. Chronic Obstr Pulm Dis. 2016;4:45-55. doi:10.15326/jcopdf.4.1.2016.0126

25. Rabin R, de Charro F. EQ-5D: a measure of health status from the EuroQol group. Ann Med. 2001;33:337-343. doi:10.3109/078538901 09002087

26. Massy-Westropp NM, Gill TK, Taylor AW, Bohannon RW, Hill CL. Hand Grip Strength: age and gender stratified normative data in a population-based study. BMC Res Notes. 2011;4:127. doi:10.1186/ 1756-0500-4-127

27. Ong HL, Chang SHS, Abdin E, et al. Association of grip strength, upper arm circumference, and waist circumference with dementia in older adults of the WiSE study: a cross-sectional analysis. $J$ Nutr Health Aging. 2016;20:996-1001. doi:10.1007/s12603-015-0643-4 
28. Joosten E, Detroyer E, Milisen K. Effect of anaemia on hand grip strength, walking speed, functionality and 1 year mortality in older hospitalized patients. BMC Geriatr. 2016;16:153. doi:10.1186/ s12877-016-0326-y

29. Ji C, Zheng L, Zhang R, Wu Q, Zhao Y. Handgrip strength is positively related to blood pressure and hypertension risk: results from the national health and nutrition examination survey. Lipids Health Dis. 2018;17:86. doi:10.1186/s12944-018-0734-4

30. Xu L, Hao YT. Effect of handgrip on coronary artery disease and myocardial infarction: a Mendelian randomization study. Sci Rep. 2017;7:954. doi:10.1038/s41598-017-01073-Z

31. Marques LP, Confortin SC, Ono LM, Barbosa AR, d'Orsi E. Quality of life associated with handgrip strength and sarcopenia: epiFloripa aging study. Arch Gerontol Geriatr. 2019;81:234-239. doi:10.1016/j. archger.2018.12.015

32. Kostikas K, Bakakos P, Papiris S, Stolz D, Celli BR. Systemic biomarkers in the evaluation and management of COPD patients: are we getting closer to clinical application? Curr Drug Targets. 2013;14:177-191. doi:10.2174/1389450111314020005

33. Guerra S, Halonen M, Vasquez MM, et al. Relation between circulating $\mathrm{CC} 16$ concentrations, lung function, and development of chronic obstructive pulmonary disease across the lifespan: a prospective study. Lancet Respir Med. 2015;3:613-620. doi:10.1016/S22132600(15)00196-4

34. Smith L, Yang L, Hamer M. Handgrip strength, inflammatory markers, and mortality. Scand J Med Sci Sports. 2019;29:1190-1196. doi:10.1111/sms. 13433

35. Harada H, Kai H, Shibata R, et al. New diagnostic index for sarcopenia in patients with cardiovascular diseases. PLoS One. 2017;12: e0178123. doi:10.1371/journal.pone.0178123
36. Hallin R, Janson C, Arnardottir RH, et al. Relation between physical capacity, nutritional status and systemic inflammation in COPD. Clin Respir J. 2011;5:136-142. doi:10.1111/j.1752-699X.2010.00208.x

37. Burtin C, Ter Riet G, Puhan MA, et al. Handgrip weakness and mortality risk in COPD: a multicentre analysis. Thorax. 2016;71:86-87. doi:10.1136/thoraxjnl-2015-207451

38. Sue DY. Peripheral muscle dysfunction in patients with COPD: comparing apples to apples? Chest. 2003;124:1-4. doi:10.1378/ chest.124.1.1

39. LoMauro A, Aliverti A. Sex differences in respiratory function. Breathe (Sheff). 2018;14:131-140. doi:10.1183/20734735.000318

40. Triebner K, Matulonga B, Johannessen A, et al. Menopause is associated with accelerated lung function decline. Am J Respir Crit Care Med. 2017;195:1058-1065. doi:10.1164/rccm.201605-0968OC

41. Qaisar R, Renaud G, Hedstrom Y, et al. Hormone replacement therapy improves contractile function and myonuclear organization of single muscle fibres from postmenopausal monozygotic female twin pairs. J Physiol. 2013;591:2333-2344. doi:10.1113/jphysiol. 2012.250092

42. Medinas Amoros M, Mas-Tous C, Renom-Sotorra F, et al. Healthrelated quality of life is associated with COPD severity: a comparison between the GOLD staging and the BODE index. Chron Respir Dis. 2009;6:75-80. doi:10.1177/1479972308101551

43. Boyer L, Bastuji-Garin S, Chouaid C, et al. Are systemic manifestations ascribable to COPD in smokers? A structural equation modeling approach. Sci Rep. 2018;8:8569. doi:10.1038/s41598-018-26766-x

44. Martinez CH, Diaz AA, Meldrum CA, et al. Handgrip strength in chronic obstructive pulmonary disease. Associations with acute exacerbations and body composition. Ann Am Thorac Soc. 2017;14:1638-1645. doi:10.1513/AnnalsATS.201610-821OC

\section{Publish your work in this journal}

The International Journal of COPD is an international, peer-reviewed journal of therapeutics and pharmacology focusing on concise rapid reporting of clinical studies and reviews in COPD. Special focus is given to the pathophysiological processes underlying the disease, intervention programs, patient focused education, and self management protocols. This journal is indexed on PubMed Central, MedLine and CAS. The manuscript management system is completely online and includes a very quick and fair peer-review system, which is all easy to use. Visit http://www.dovepress.com/testimonials.php to read real quotes from published authors. 